\title{
AKTIVITAS DAN SYNOMORPHY PADA RUANG PUBLIK KAMPUNG WARNA-WARNI JODIPAN KOTA MALANG
}

\author{
Nur Ratih Ratnawati \\ Mahasiswa Program Magister Jurusan Arsitektur Lingkungan Binaan Fakultas Teknik \\ Universitas Brawijaya \\ e-mail:nur.ratiih@gmail.com \\ Lisa Dwi Wulandari \\ Dosen Program Magister Jurusan Arsitektur Lingkungan Binaan Fakultas Teknik \\ Universitas Brawijaya \\ e-mail: lisaromansya@ub.ac.id \\ Antariksa \\ Dosen Program Magister Jurusan Arsitektur Lingkungan Binaan Fakultas Teknik \\ Universitas Brawijaya \\ e-mail: antariksa@ub.ac.id
}

\begin{abstract}
ABSTRAK
Kampung Warna-Warni Jodipan merupakan salah satu kampung di Kota Malang yang berkembang menjadi kampung wisata. Perkembangan tersebut mendorong terbentuknya aktivitas baru di dalam kampung, khususnya di ruang publiknya, yang didominasi oleh pelaku wisatawan. Aktivitas baru tersebut perlu dianalisis kesesuaiannya (synomorphy) dengan lingkungan fisik kampung yang memiliki kepadatan cukup tinggi. Penelitian ini bertujuan untuk menganalisis aktivitas dan synomorphy yang terbentuk di ruang publik kampung sehubungan dengan perkembangan fungsi kampung. Metode yang digunakan adalah kualitatif deskriptif dengan metode pengumpulan data menggunakan teknik observasi dan dokumentasi. Data yang terkumpul dianalisis secara deskriptif. Dari penelitian ini dapat disimpulkan bahwa hubungan kesesuaian antara aktivitas dan lokasi aktivitas (milieu) yang disebut dengan synomorphy, terbentuk dengan adanya unsur-unsur, physical forces, social forces, physiognomic perception, influence of behavior on the milieu serta physiological processes.
\end{abstract}

Kata kunci : aktivitas, ruang publik, synomorphy

\begin{abstract}
Kampung Warna-Warni Jodipan is one of kampong in Malang that has developed into a tourist kampong. These developments led to the formation of new activities within the kampong, especially in their public spaces, which were dominated by tourists. The new activity needs to be analyzed for its suitability (synomorphy) with the kampong's physical environment which has a fairly high density. This study aims to analyze activities and synomorphy formed in kampong public spaces due to the development of kampong functions. The method used is descriptive qualitative with data collection methods using observation and documentation techniques. The collected data was analyzed descriptively.
\end{abstract}

PAWON: Jurnal Arsitektur, Nomor -- Volume --, Bulan Tahun, ISSN 2597-7636 
From this study, it can be concluded that the relationship between the activity and location of activities (milieu), called synomorphy, is formed by physical forces, social forces, physiological perception, the influence of behavior on the milieu and physiological processes.

Keywords : activity, public space, synomorphy,

\section{PENDAHULUAN}

Kampung Warna-Warni Jodipan merupakan salah satu kampung wisata di Kota Malang yang terletak dekat dengan pusat kota dan secara administratif berada di Kelurahan Jodipan, Kecamatan Blimbing. Kampung ini sebelumnya dikenal dengan sebutan Kampung Juanda karena berbatasan langsung dengan JI. Ir. H. Juanda di sebelah selatan kampung. Sedangkan bagian utara kampung berbatasan langsung dengan Sungai Brantas.

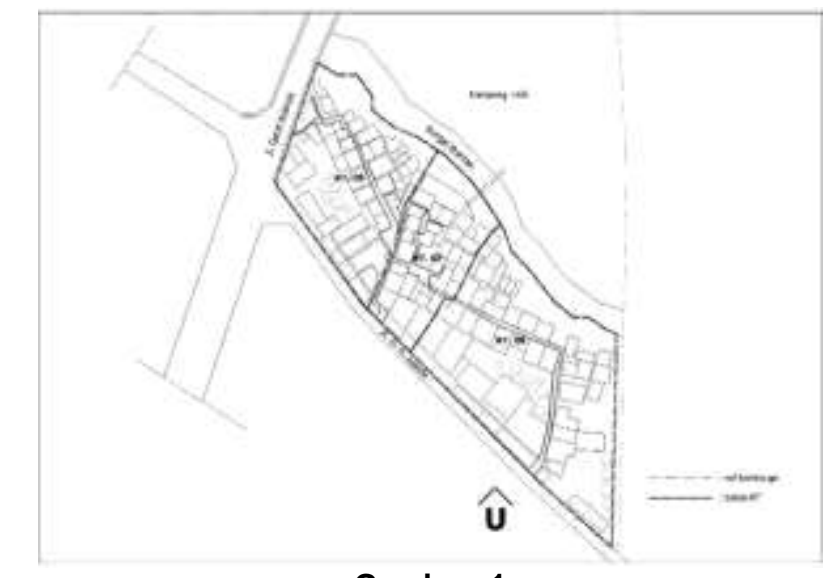

Gambar. 1

Peta lokasi Kampung Warna-Warni Jodipan Kota Malang Sumber: data diolah, 2018

Sebelum menjadi kampung wisata, kampung ini masuk dalam kategori kampung kumuh di Kota Malang dengan kondisi fisik yang tidak memadai (kepadatan bangunan dan penduduk tinggi, kurangnya sarana prasarana) dan perilaku masyarakat yang terbiasa membuang sampah di sungai. Hingga pada akhirnya muncul gagasan dari mahasiswa Universitas Muhammadiyah Malang untuk menghilangkan image negatif dan kesan kumuh pada kampung ini dan mewujudkan keindahan dan kebersihan kampung, serta meningkatkan kreativitas dan partisipasi dari masyarakat kampung. Realisasi gagasan ini diawali dengan melakukan kerjasama dengan perusahaan cat di Kota Malang melalui program CSR (Corporate Social Responsibility). Selanjutnya dilakukan pengecatan pada dindingdinding, atap bangunan, dan jalan di Kampung Juanda menggunakan warna

PAWON: Jurnal Arsitektur, Nomor -- Volume --, Bulan Tahun, ISSN 2597-7636 
yang mencolok dan beragam. Setelah dilakukan pengecatan, Kampung Juanda menjadi lebih menarik, berkesan rapi, bersih, indah dan menarik perhatian warga yang mmelintas untuk berkunjung. Kampung ini kemudian menjadi kampung wisata dan kini lebih dikenal dengan sebutan Kampung Warna-Warni Jodipan. Pemerintah Kota Malang yang semula berencana untuk menggusur kampung ini turut serta dalam meresmikan kampung ini menjadi kampung wisata.

Selain mengecat dengan warna yang mencolok dan beragam, warga kampung juga menghias ruang publik kampung dengan atribut-atribut ruang, baik dengan atribut yang bersifat tetap (fix) maupun semi fix (Rapoport, 1982). Atribut/ elemen tersebut kemudian digunakan wisatawan untuk melakukan aktivitas-aktivitas. Barker (1968) mengembangkan teori mengenai pola perilaku manusia berkaitan dengan tatanan lingkungan fisiknya dan melahirkan konsep "tatar perilaku" (behavior setting). Namun tidak setiap tempat merupakan behavior setting (Heft, 2001). Dalam behavior setting terdapat unsur synomorphy, yaitu kesesuaian antara pola perilaku dengan lingkungan (milieu) dalam hal bentuk dan struktur. Synomorphy menunjukkan bagaimana lingkungan menciptakan suasana spesifik untuk mendukung perilaku pengguna. Komponen perilaku dan milieu pada behavior setting tidak tersusun secara independen, melainkan terdapat kesesuaian di antara keduanya.

Dalam penelitian ini, Kampung Warna-Warni dipilih sebagai lokasi studi dengan pertimbangan kampung ini merupakan kampung yang mengawali perkembangan kampung wisata di Kota Malang, khususnya yang terletak di area sempadan sungai. Objek studi adalah ruang publik di Kampung Warna-Warni Jodipan berupa jalan kampung. Jalan kampung yang dipilih sebagai sampel adalah jalan kampung dari pintu masuk yang berbatasan langsung dengan jalan utama kota (Jl. Gatot Subroto). Objek penelitian dapat dilihat pada Gambar 2. Area ini diambil 3 titik pengamatan dengan pertimbangan banyak wisatawan yang beraktivitas di titik-titik tersebut.

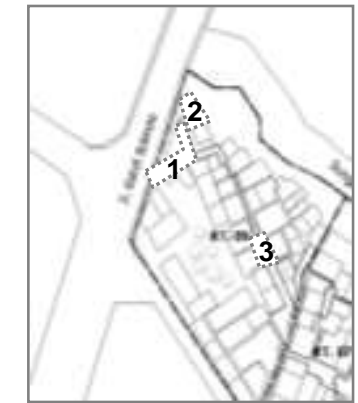

Gambar. 2

Objek penelitian

Sumber: data diolah, 2018 
Perkembangan kampung menjadi kampung wisata mendorong terbentuknya aktivitas baru di dalam kampung, khususnya di ruang publiknya, yang didominasi oleh pelaku wisatawan. Aktivitas baru tersebut perlu dianalisis kesesuaiannya (synomorphy) dengan lingkungan fisik kampung yang memiliki kepadatan yang cukup tinggi. Penelitian ini bertujuan untuk menganalisis aktivitas dan synomorphy yang terbentuk di ruang publik kampung sehubungan dengan perkembangan fungsi kampung., sehingga akan diketahui objek-objek/ tempat-tempat mana saja di ruang publik kampung yang digunakan oleh wisatawan untuk melakukan aktivitas wisata.

\section{TINJAUAN PUSTAKA}

\subsection{RUANG PUBLIK KAMPUNG}

Ruang publik merupakan bagian dari ruang kota (urban space) dimana seluruh masyarakat mempunyai akses untuk menggunakannya sebagai wadah aktivitas sosial baik secara individu maupun berkelompok (Krier, 1979; Hakim, 1987). Ruang publik di kampung lebih dikenal sebagai ruang bersama yang digunakan sebagai wadah aktivitas sosial yang didasari rasa kebersamaan dan keguyuban. Ruang bersama dapat dikatakan sebagai shared space atau ruang berbagi bersama (Prijotomo \& Pangarsa 2010). Pada masyarakat kampung kota, ruang bersama biasa digunakan untuk meletakkan barang, menjemur pakaian, tempat bermain anak, memasak bersama dan pengajian, berjualan, peringatan 17 Agustus maupun hari besar agama, serta menampung tamu pada penyelenggaraan pesta dan acara besar lainnya (Titisari, 2012). Aktivitas-aktivitas tersebut biasanya dilakukan di ruang jalan yang bernama gang ataupun di ruang terbuka di sekitar rumah. Sifat ruang bersama dapat dikategorikan sebagai ruang publik karena dalam hal pemanfaatannya tidak bersifat pribadi namun dapat digunakan oleh sekelompok orang secara umum (Indeswari et al, 2013).

\subsection{AKTIVITAS DI RUANG PUBLIK}

Menurut Carr et al (1992), ruang publik dalam suatu permukiman akan berperan atau berfungsi secara baik apabila memiliki unsur:

1. Pasive engagement, unsur ini sangat dipengaruhi oleh kondisi lingkungan ruang publik. Keterlibatan pasif dapat diwujudkan dalam bentuk melakukan aktivitas pasif seperti duduk-duduk, berdiri sambil mengamati aktivitas yang ada di sekeliling, atau melihat pemandangan yang berupa taman, air mancur, patung, serta karya seni yang lain.

2. Active engagement, meliputi pengalaman langsung dengan tempat dan orang-orang yang berada di tempat tersebut. Suatu ruang publik dapat dikatakan berhasil apabila dapat mewadahi aktivitas dan interaksi sosial antar pengguna baik yang sudah saling mengenal

PAWON: Jurnal Arsitektur, Nomor -- Volume --, Bulan Tahun, ISSN 2597-7636 
ataupun belum. Di samping itu, pengaturan elemen-elemen ruang publik seperti tempat duduk, air mancur, patung, hingga pedagang akan turut mempengaruhi interaksi sosial yang terjadi.

\subsection{SYNOMORPHY}

Barker melihat kesesuaian antara perilaku ekstraindividual dengan lingkungan (milieu) yang ia sebut dengan synomorphy. Perilaku ekstraindividual menunjukkan fakta operasional bahwa sebuah lingkungan tidak hanya bergantung pada seorang manusia/ individu (Laurens, 2004), artinya sebuah pola perilaku akan tetap berlangsung di suatu tempat meskipun pelakunya berganti. Misal, aktivitas yang terjadi di sebuah POM bensin, aktivitas yang terjadi di dalam kelas, dan sebagainya.

Menurut Schoggen (1989) synomorphy dapat terjadi dengan adanya unsur-unsur berikut:

a. Physical forces. Tatanan fisik pada sebuah lingkungan dapat mendorong maupun mencegah terbentuknya suatu pola perilaku. Sebagai contoh, sebuah koridor memungkinkan pergerakan menuju arah tertentu, area yang sempit, mencegah adanya aktivitas bergerombol.

b. Social forces. Aspek sosial merupakan salah satu unsur yang dapat dengan sangat kuat mendorong terbentuknya perilaku. Kekuatan sosial juga mendorong perilaku seseorang untuk menyesuaikan diri dalam situasi tertentu. Misal, pada sebuah ruangan kelas, ketika semua murid duduk, murid yang baru datang juga akan duduk; ketika semua diam/ tenang, maka keinginan untuk berisik/ ribut akan ditahan.

c. Physiological processes. Terdapat mekanisme dalam diri seseorang yang secara otomatis merespon kondisi fisik-geografis dari sebuah lingkungan (milieu).

d. Physiognomic perception. Perilaku terjadi karena persepsi seseorang terhadap stimuli/ rangsangan yang berasal dari lingkungan. Lingkungan sendiri juga ditata untuk menimbulkan persepsi yang mendorong penggunaan yang sesuai dengan maksud penataan.

e. Learning. Proses belajar merupakan salah satu faktor yang dapat menciptakan synomorphy.

f. Selection of setting by persons. Seseorang dapat memilih untuk terlibat atau tidak terlibat dalam behavior setting tertentu.

g. Selection of persons by behavior setting. Behavior setting juga dapat terbatas bagi beberapa orang. Misal, anak yang berusia di bawah 5 tahun tidak diijinkan mendaftar sekolah dasar, anak yang tingginya kurang dari $90 \mathrm{~cm}$ tidak boleh naik wahana tertentu dalam taman hiburan, dan sebagainya. 
h. Influence of behavior on the milieu. Terkadang perilaku seseorang dalam sebuah lingkungan binaan tidak sesuai dengan maksud dari perancang yang membuat desain lingkungan tersebut. Namun hal ini dapat menjadi synomorphy ketika perilaku tersebut kemudian dilakukan pula oleh banyak orang dan lingkungan yang ada disesuaikan dengan aktivitas yang ada.

\section{METODE PENELITIAN}

Penelitian ini menggunakan metode kualitatif deskriptif. Karakteristik utama penelitian kualitatif adalah objek penelitian berasal dari kondisi alami/ kenyataan di masyarakat dengan langkah pengamatan atau observasi secara langsung di lapangan, wawancara, dan penelaahan data. Sedangkan metode deskriptif bertujuan mendeskripsikan keadaan atau fenomena yang terjadi pada objek kajian dengan tujuan utama menggambarkan secara sistematis fakta-fakta dan karakteristik objek kajian.

Data dibedakan menjadi dua, yaitu data primer dan data sekunder. Data primer adalah data yang diperoleh langsung dari lapangan, sedangkan data sekunder adalah data yang melengkapi data primer, yaitu yang diperoleh dari instansi terkait maupun dari internet berupa buku/ dokumen/ catatan yang diteliti atau suatu hasil penelitian. Data primer dikumpulkan dengan cara observasi/ pengamatan langsung pada objek studi. Objek amatan berupa aktivitas yang dilakukan oleh wisatawan di ruang publik Kampung Warna-Warni Jodipan. Data sekunder berupa peta lokasi penelitian dan teori-teori yang berhubungan dengan topik penelitian diperoleh dari internet dan buku.

Observasi dilakukan dengan langkah-langkah:

a. Membuat sketsa dasar area yang diamati;

b. Pengamatan dilakukan pada saat banyak pengunjung, yaitu hari libur;

c. Peneliti memilih lokasi pengamatan yang memiliki visibilitas tinggi untuk mengamati aktivitas yang terjadi,

d. Peneliti mendokumentasikan aktivitas yang terjadi.

Data yang telah diperoleh kemudian dianalisis secara deskriptif.

\section{HASIL DAN PEMBAHASAN}

\subsection{Synomorphy pada Lokasi 1}

Lokasi 1 merupakan area penerima dari pintu masuk kampung. Area ini berupa jalan yang cukup curam dengan anak tangga, serta ada bagian yang berupa dinding yang dicat dengan mural dan dengan pola-pola tertentu. 


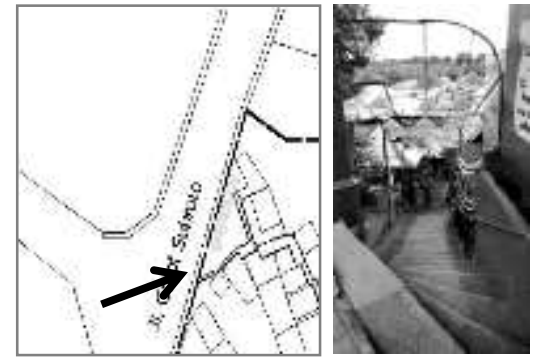

Gambar. 3

Lokasi 1

Sumber: data diolah, dokumentasi pribadi, 2018

. Aktivitas dan synomorphy yang terjadi pada area ini antara lain:

Tabel 1.

Analisis synomorphy pada lokasi 1

\begin{tabular}{|c|c|c|c|}
\hline No. & Aktivitas - Milieu & Foto & Analisis Synomorphy \\
\hline 1. & $\begin{array}{l}\text { Menjual dan } \\
\text { membeli tiket masuk }\end{array}$ & & $\begin{array}{l}\text { Perkembangan kampung menjadi } \\
\text { kampung wisata membuat warga } \\
\text { memberlakukan tiket masuk bagi } \\
\text { wisatawan untuk biaya perawatan } \\
\text { kampung, sehingga terjadi aktivitas } \\
\text { jual-beli tiket masuk pada spot yang } \\
\text { terletak di dekat pintu masuk ini. } \\
\text { Synomorphy terbentuk dengan } \\
\text { adanya unsur influence of behavior } \\
\text { on the milieu. }\end{array}$ \\
\hline 2. & Berfoto di tangga & & $\begin{array}{l}\text { Jalan kampung yang berupa anak } \\
\text { tangga yang dicat dengan beberapa } \\
\text { warna yang berbeda menjadi spot } \\
\text { yang menarik bagi wisatawan untuk } \\
\text { melakukan aktivitas berfoto. } \\
\text { Jalan kampung yang berfungsi } \\
\text { sebagai jalur sirkulasi menjadi spot } \\
\text { foto yang menarik, synomorphy } \\
\text { terbentuk karena adanya unsur } \\
\text { physiognomic perception }\end{array}$ \\
\hline 3. & $\begin{array}{l}\text { Berfoto dengan latar } \\
\text { dinding mural }\end{array}$ & & $\begin{array}{l}\text { Masyarakat Kampung Warna-Warni } \\
\text { Jodipan menghias dinding-dinding } \\
\text { bangunan dengan menggunakan } \\
\text { mural sehingga dapat digunakan } \\
\text { wisatawan untuk berfoto. } \\
\text { Pada spot ini, synomorphy terbentuk } \\
\text { dengan adanya unsur physical } \\
\text { forces. }\end{array}$ \\
\hline
\end{tabular}

PAWON: Jurnal Arsitektur, Nomor -- Volume --, Bulan Tahun, ISSN 2597-7636 


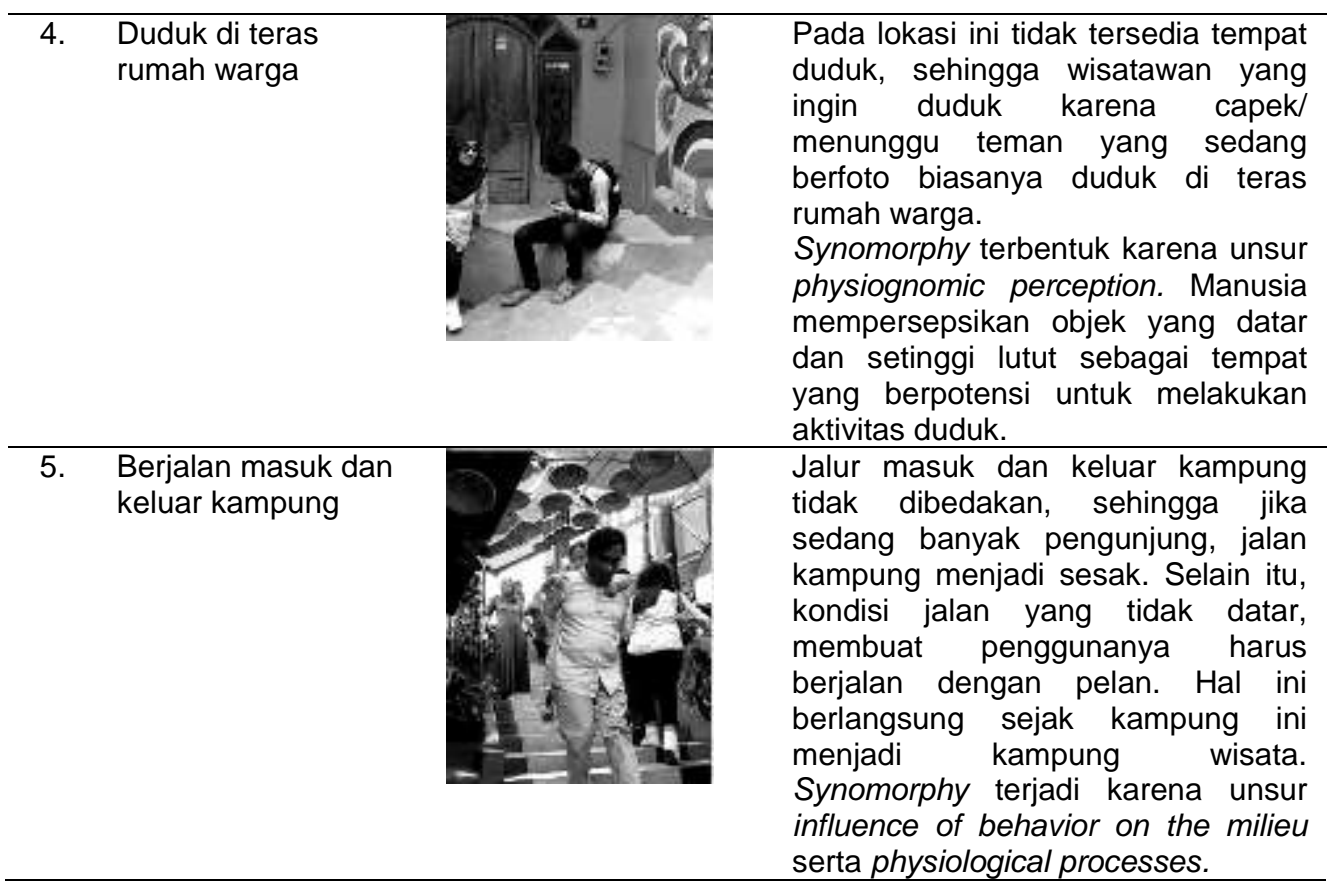

\subsection{Synomorphy pada Lokasi 2}
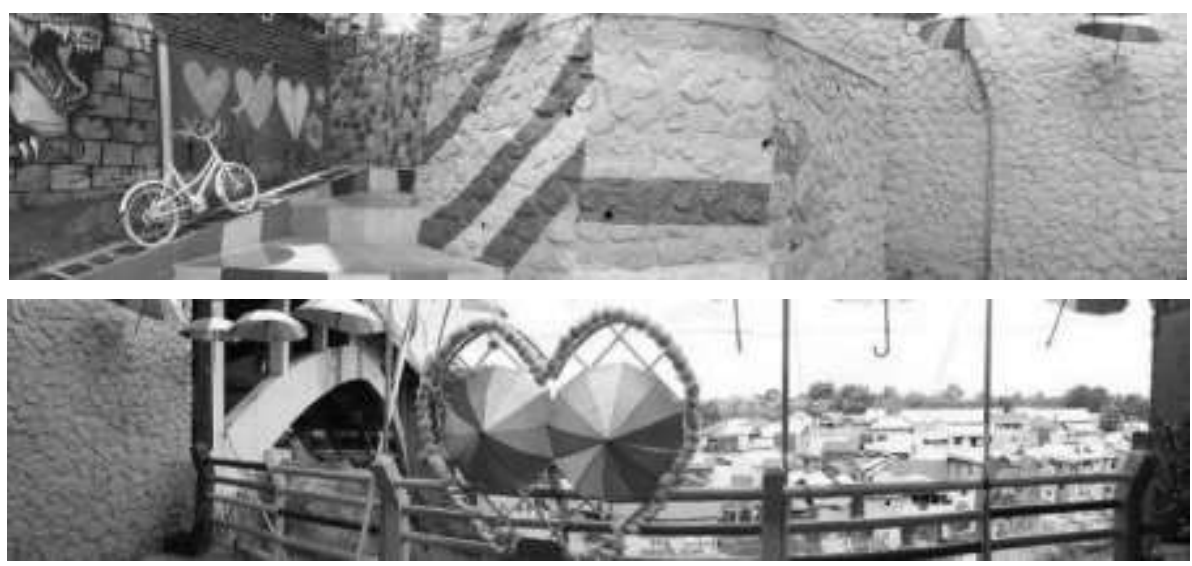

\section{Gambar. 4 \\ Lokasi 2}

Sumber: dokumentasi pribadi, 2018

Lokasi 2 merupakan sebuah area terbuka di bagian barat kampung yang memiliki view ke arah Sungai Brantas dan Kampung Tridi yang ada di seberang Kampung Warna-Warni. Lokasi ini ditata oleh warga untuk menjadi spot foto yang menarik. Aktivitas dan synomorphy yang terjadi di lokasi ini antara lain: 
Tabel 2.

Analisis synomorphy pada lokasi 2

\begin{tabular}{|c|c|c|c|}
\hline No. & Aktivitas - Milieu & Foto & Analisis Synomorphy \\
\hline 1. & $\begin{array}{l}\text { Berfoto dengan latar } \\
\text { instalasi }\end{array}$ & & $\begin{array}{l}\text { Instalasi yang terbuat dari rangkaian } \\
\text { besi dengan bentuk hati dan hiasan } \\
\text { berupa payung warna-warni dan } \\
\text { tanaman plastik menjadi spot yang } \\
\text { sering digunakan oleh wisatawan } \\
\text { untuk berfoto. } \\
\text { Synomorphy terbentuk karena } \\
\text { adanya unsur physical forces, yaitu } \\
\text { adanya penataan lingkungan, } \\
\text { sehingga mendorong terbentuknya } \\
\text { aktivitas tertentu. }\end{array}$ \\
\hline 2. & $\begin{array}{l}\text { Berfoto dengan } \\
\text { intalasi sepeda } \\
\text { bekas dan latar } \\
\text { dinding bermural }\end{array}$ & & $\begin{array}{l}\text { Instalasi berupa sepeda bekas } \\
\text { dengan dinding yang dihiasi mural } \\
\text { menjadi spot yang biasa digunakan } \\
\text { untuk berfoto oleh wisatawan. } \\
\text { Synomorphy terbentuk karena } \\
\text { adanya unsur physical forces, yaitu } \\
\text { adanya penataan lingkungan, } \\
\text { sehingga mendorong terbentuknya } \\
\text { aktivitas tertentu. }\end{array}$ \\
\hline 3. & $\begin{array}{l}\text { Berfoto dengan latar } \\
\text { dinding warna-warni }\end{array}$ & & $\begin{array}{l}\text { Dinding plengsengan batu yang dicat } \\
\text { warna-warni juga menjadi spot yang } \\
\text { menarik untuk melakukan aktivtas } \\
\text { berfoto. } \\
\text { Pada spot ini, synomorphy terbentuk } \\
\text { dengan adanya unsur physical } \\
\text { forces. }\end{array}$ \\
\hline 4. & $\begin{array}{l}\text { Melihat } \\
\text { pemandangan ke } \\
\text { arah sungai dan } \\
\text { Kampung Tridi }\end{array}$ & & $\begin{array}{l}\text { Potensi view yang ada di lokasi } 2 \text { ini } \\
\text { mendorong adanya aktivitas melihat- } \\
\text { lihat/ menikmati pemandangan. } \\
\text { Synomorphy terbentuk karena unsur } \\
\text { physiognomic perception. View yang } \\
\text { menarik membuat seseorang ingin } \\
\text { menikmati. }\end{array}$ \\
\hline 5. & $\begin{array}{l}\text { Duduk beristirahat di } \\
\text { kursi properti foto }\end{array}$ & & $\begin{array}{l}\text { Adanya kursi di spot ini tidak jarang } \\
\text { digunakan wisatawan untuk duduk } \\
\text { beristirahat akibatnya wisatawan lain } \\
\text { yang ingin menggunakan sspot } \\
\text { tersebut untuk berfoto berpindah ke } \\
\text { spot lain. } \\
\text { Aktivitas ini tidak bersesuaian } \\
\text { dengan milieu karena mengganggu } \\
\text { aktivitas yang lain. }\end{array}$ \\
\hline
\end{tabular}

Sumber: hasil analisis, 2018

PAWON: Jurnal Arsitektur, Nomor -- Volume --, Bulan Tahun, ISSN 2597-7636 


\subsection{Synomorphy pada Lokasi 3}
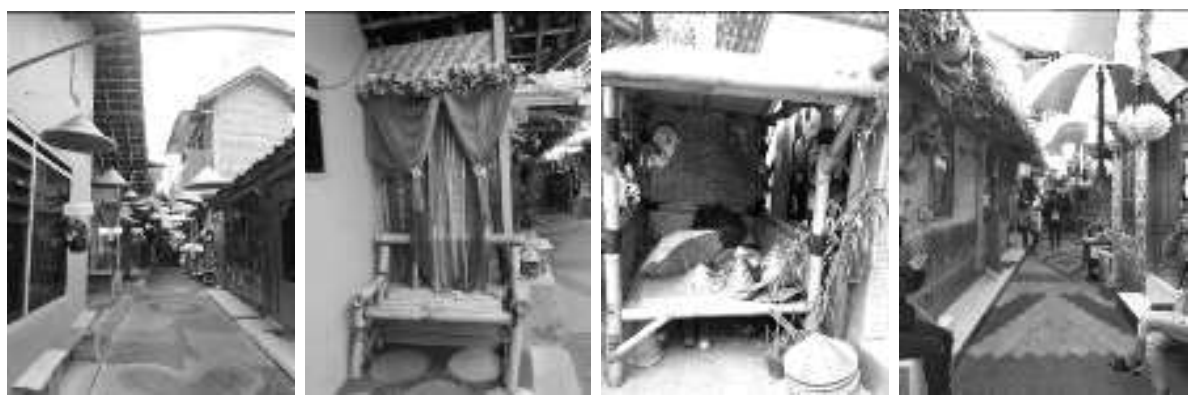

\section{Gambar. 5}

Lokasi 3

Sumber: dokumentasi pribadi, 2018

Lokasi 3 merupakan bagian jalan kampung yang ditata oleh warga dengan menambahkan elemen dekorasi berupa topeng-topeng khas Malang dan topi bambu yang digantung di atas jalan. Di lokasi ini juga terdapat sebuah gazebo dengan beberapa properti yang disediakan untuk berfoto, seperti topi bambu, dan tulisan-tulisan. Selain itu, juga ada rumah yang dihias dengan anyaman bambu pada dindingnya. Aktivitas dan synomorphy yang terjadi pada lokasi ini antara lain:

Tabel 3.

Analisis synomorphy pada lokasi 3

\begin{tabular}{clll}
\hline No. Aktivitas - Milieu & \multicolumn{1}{c}{ Analisis Synomorphy } \\
\hline 1. $\begin{array}{l}\text { Berfoto dengan } \\
\text { properti topeng } \\
\text { Malangan. }\end{array}$ & $\begin{array}{l}\text { Penambahan elemen non fix berupa } \\
\text { topeng Malangan di jalan kampung } \\
\text { membentuk aktivitas berfoto di sana. } \\
\text { Namun pada saat kunjungan ramai, } \\
\text { aktivitas berfoto dan berjalan kaki } \\
\text { harus berjalan bergantian. } \\
\text { Synomorphy terbentuk karena } \\
\text { adanya unsur physical forces, dan } \\
\text { influence of behavior on the milieu. }\end{array}$ \\
\hline $\begin{array}{l}\text { Berfoto dengan latar } \\
\text { dinding anyaman } \\
\text { bambu }\end{array}$ & $\begin{array}{l}\text { Penambahan elemen non fix berupa } \\
\text { anyaman bambu pada dinding } \\
\text { rumah warga membentuk aktivitas } \\
\text { berfoto di sana. Namun pada saat } \\
\text { ada orang yang melintas, aktivitas } \\
\text { berfoto dan berjalan kaki harus } \\
\text { berjalan bergantian. } \\
\text { Synomorphy terbentuk karena } \\
\text { adanya unsur physical forces, dan } \\
\text { influence of behavior on the milieu. }\end{array}$ \\
\hline
\end{tabular}

PAWON: Jurnal Arsitektur, Nomor -- Volume --, Bulan Tahun, ISSN 2597-7636 


\begin{tabular}{|c|c|c|}
\hline 3. & Merapikan spot foto & $\begin{array}{l}\text { Wisatawan yang melakukan aktivitas } \\
\text { berfoto tidak jarang tidak merapikan } \\
\text { spot foto yang digunakan, sehingga } \\
\text { warga setempat yang lokasi } \\
\text { rumahnya dekat dengan spot } \\
\text { tersebut berinisiatif untuk merapikan } \\
\text { agar lokasi tersebut tetap menarik. } \\
\text { Pada spot ini, synomorphy terbentuk } \\
\text { dengan adanya unsur social forces. }\end{array}$ \\
\hline & $\begin{array}{l}\text { Bermain di jalan } \\
\text { kampung }\end{array}$ & $\begin{array}{l}\text { Jalan kampung juga berfungsi } \\
\text { sebagai tempat bermain bagi anak- } \\
\text { anak di Kampung Warna-Warni } \\
\text { Jodipan. } \\
\text { Synomorphy terbentuk karena unsur } \\
\text { physical forces, artinya kondisi } \\
\text { kampung yang padat memaksa } \\
\text { anak-anak untuk menggunakan jalan } \\
\text { kampung untuk aktivitas bermain. }\end{array}$ \\
\hline
\end{tabular}

Sumber: hasil analisis, 2018

\section{KESIMPULAN}

Kampung Warna-Warni Jodipan Kota Malang telah berhasil menjadi destinasi wisata baru di dalam kota. Hal ini ditunjukkan dengan banyaknya wisatawan yang datang setiap harinya. Penataan yang dilakukan di ruang publik kampung mendorong terbentuknya aktivitas di dalamnya, yang terjadi secara berulang sejak kampung ini menjadi kampung wisata. Aktivitas yang paling banyak dilakukan oleh wisatawan adalah berfoto karena banyak spot foto yang disediakan di kampung ini. Aktivitas lain yang biasa dilakukan oleh wisatawan adalah melihat-lihat pemandangan, berjalan masuk dan keluar kampung, membeli tiket serta duduk-duduk. Aktivitas yang dilakukan warga setempat pada sampel lokasi penelitian adalah menjual tiket dan merapikan spot foto. Hubungan kesesuaian antara aktivitas dan lokasi aktivitas (milieu) yang disebut dengan synomorphy, terbentuk dengan adanya unsur-unsur, physical forces, physiognomic perception, influence of behavior on the milieu serta physiological processes.

\section{DAFTAR PUSTAKA}

Barker, R. G. 1968. Ecological Psychology: Concepts and Methods for Studying the Environment of Human Behavior. Stanford, CA: Stanford University Press.

Gibson, J. J. 1979. The Ecological Approach to Visual Perception. Hillsdale, New Jersey: Lawrence Erlbaum.

Hakim, Rustam. 1987. Unsur Perancangan (Dalam Arsitektur Lansekap). Jakarta: Bumi Aksara.

PAWON: Jurnal Arsitektur, Nomor -- Volume --, Bulan Tahun, ISSN 2597-7636 
Heft, H. 2001. Ecological Psychology in Context. James Gibson, Roger Barker, and the Legacy of William James's Radical Empiricism. New Jersey: Lawrence Erlbaum Associates.

Indeswari, A., Antariksa, Pangarsa, G. W., Wulandari, L. D. 2013. Pola Ruang Bersama pada Permukiman Madura Medalungan di Dusun Baran Randugading. Jurnal RUAS, Volume 11 No 1.

Krier, Rob. 1979. Urban Space. London: Academy Edition.

Ningsih, T.R. 2017. Kampung Wisata Warna Warni Jodipan Kota Malang, Berkelanjutan atau Sementara?. Prosiding SCAN\#8, Universitas Atma Jaya Yogyakarta, 19 Oktober 2017.

Prijotomo, J. \& Pangarsa, G. W. 2010. Rong: Wacana Ruang Arsitektur Jawa. E-book Engine. ( www.ruangarsitektur.com, diakses 12 Agustus 2018).

Rapoport, A. 1982. The Meaning of The Built Enviroment. California: SAGE Publications.

Schoggen, P. 1989. Behavior Settings: A Revision and Extension of Roger G. Barker's Ecological Psychology. Stanford, CA: Stanford University Press.

Titisari, EY. 2012. Ruang Bersama Pada Permukiman Di Kota Malang Studi Kasus: Kampung Kidul Dalem, Malang. 